\title{
FUNCTIONAL STATUS AND SLEEP QUALITY AMONG ELDERLY PATIENTS WITH CHRONIC OBSTRUCTIVE PULMONARY DISEASE \\ Reda Sobhy elsayed ${ }^{1}$, Aziza Mahmoud Boughdady ${ }^{2}$ and Soad Hassan \\ Abd Elhameed ${ }^{3}$ \\ ${ }^{I}$ BSc. Nursing-Faculty of Nursing-Tanta University. \\ ${ }^{2}$ Assist. Prof. of Gerontological Nursing-Faculty of Nursing-Mansoura University. \\ ${ }^{3}$ Assist. Prof. of Gerontological Nursing-Faculty of Nursing-Mansoura University- Egypt.
}

\begin{abstract}
Background: Chronic obstructive pulmonary disease (COPD) considering one of the most chronic disease affecting elderly patients all over the world. Chronic obstructive pulmonary disease is a major worldwide public health problem for increasing its mortality and morbidity. Aim: Determine the functional status and quality of sleep among elderly patients with chronic obstructive pulmonary disease. Method: A descriptive research design was used in this study. This study was conducted at kafr El sheikh Chest Hospital affiliated to the Ministry of health. A convenience sample of 116 elderly patients diagnosed with chronic obstructive pulmonary disease admitted to the above-mentioned setting within a period of six months. Tools: Data was collected by using three tools; demographic and clinical data structured interview schedule,_Functional Independence Measure and Pittsburgh Sleep Quality Index. Results: The mean of age in the studied elderly patients was 70.05 \pm .08 years in addition the mean score of patients' functional status was $62.2 \pm$ 32.1. nearly three quarter of the studied elderly suffering poor quality of sleeping and nearly half of them reported that their functional status were very good . Also, there was statistically negative significant correlation between functional status and sleep quality. Conclusion: Nearly three quarters of studied elderly patients reported very good related to functional status, while, most of them reported poor quality of sleeping. quality of sleep was related to patient's functional health status. Recommendation: Development comprehensive simple Arabic printed educational materials such as (booklet, pamphlet and posters) for chronic obstructive pulmonary disease can improve functional status and quality of sleep.

Key words: Elderly, COPD, Functional status, Sleep quality.

I. Introduction

Chronic obstructive pulmonary disease (COPD) is defined by persistent air flow limitation that is usually progressive and associated with chronic inflammatory response in the air way and the lungs ${ }^{1}$. Diagnosis of chronic obstructive pulmonary disease in elderly patients is complicated because many elderly patients with the disease ignore or comparatively tolerant of their symptoms and consequently do not seek medical attention. COPD affects

approximately $16 \%$ of people over the age of 65 years. COPD is responsible for 7 deaths per 1000 individuals 65 years. Worldwide incidence and mortality rates of COPD is continue rising ${ }^{2}$.

Chronic obstructive pulmonary disease is usually related to decreased functional status and physical activity of daily livings (ADLs) and ultimately leads to sedentary life. Functional status is a multidimensional theory, which focuses on the ability to perform activity of daily livings ${ }^{3}$. When the disease advanced, the
\end{abstract}


activities becomes severely limited. COPD is typically accompanied by dyspnea which interferes with normal daily activity to decrease the intensity of distress ${ }^{4}$. The decrease in ADLS leads to deconditioning which in turn further increases of dyspnea. Dyspnea and fatigue are significant features that affecting health related quality of life. Moreover, functional status has become valued outcome measure in COPD because the functional status impaired is proven to be interpreters for exacerbations and hospital admissions. In addition, when functional status become worsening, causes a rough challenge for patients, families and increase burden on the society ${ }^{5}$

Sleep is a second common feature in COPD patients. Physiologic aging changes is interfering the quality of sleeping. The elderly patients who suffer COPD recognized to have difficulty starting and / or staying asleep, and many sleep related disturbances such as lighter sleeping, less deep sleeping such as insomnia, obstructive sleep apnea ${ }^{6}$. Physiologic changes that occur in COPD lead to fragmented sleep due to nocturnal airflow obstruction, hypercapnia, arterial oxygen desaturation and usage of accessory muscles of respiration. Majority of elderly patients with COPD have sleep efficiency ranging from 50 to $70 \%$. Elderly patients with chronic obstructive pulmonary disease commonly complain difficulty of beginning, maintaining sleep and increased number of arousals during sleep. So, it is a valuable sign in the management of COPD patients. Because sleep is an important feature of maintaining the body's circadian rhythm ${ }^{7}$.

The gerontological nurse has a critical role in helping elderly patients with COPD to improve functional status and sleep quality with chronic illness, as well educating patients to acquire new activities for daily living ${ }^{8}$. Motivating them to change their life style, adapting the reality of disease and the importance of stop smoking, enhanced gas exchange, air way clearance, activity complication, tolerance, maximal self-management, enhanced coping ability and home care ${ }^{9}$.

\section{Aim of the study}

Determine the functional status and quality of sleep among elderly patients with chronic obstructive pulmonary disease.

\section{Research questions}

1 -What is the functional status of elderly patients with chronic obstructive pulmonary disease?

2 -What is the sleep quality of elderly patients with chronic obstructive pulmonary disease?

\section{Subjects \& Method}

Research design: A descriptive research design was used in this study.

Setting: This study was conducted in kafr El sheikh Chest Hospital affiliated to the Ministry of health.

Subjects: related to participants only not sample or sample techniques elderly patients diagnosed with chronic obstructive pulmonary disease and attending to the previous setting within a period of six months.

Sampling: All patients 116 admitted to the previous hospital and suffering chronic obstructive pulmonary disease.

Sample techniques A convenience sample. Elderly patients characterized Inclusion criteria:

Patients aged sixty years and more, diagnosed with COPD for one year or more.

Patients accepted to participate in the study voluntarily. 
Patients able to communicate and free from any other respiratory disease such as lung cancer and free from any associated disorders such as heart failure and coronary artery disease.

Tools: In order to collect the necessary information for the study, three tools were used:

Tool 1: Demographic and clinical data structured interview schedule. It was established by the researcher after literature reviewing and includes 2 parts.

Part 1: Demographic characteristics of the studied elderly patients as age, sex, marital status, level of education, current occupation, occupation before retirement, living arrangement and income.

Part 2: Medical history of the studied elderly such as the duration of the disease, complaints, date of admissions, date of discharge, previous hospital admission, family history of COPD or any other chronic respiratory diseases and exposure to risk factors.

Tool 2: Functional Independence Measure (FIM Instrument).

This tool was adopted from the American Congress of Rehabilitation Medicine and the American Academy of Physical Medicine and Rehabilitation and published by Hamilton et al., (1987) $^{10}$ and the Center for Medicare and Medicaid Services (2003) ${ }^{11}$. It was converted into Arabic language and tested for validity and reliability by Shebl \& Abd Elhameed, (2014) ${ }^{12}$. The reliability was confident by spearman's correlation coefficient $(\mathrm{r}=0.95)$. This tool is one of the most widely used disability and dependence assessment instruments in rehabilitation medicine and is secondhand to measure the functional status of the elderly patients. It contains eighteen items comprises six areas: self- care, sphincter control, transfers, locomotion, communication and social cognition. Totally items are recorded from 1 to 7 levels of function, fluctuating from complete dependence (level 1) to complete independence (level 7). The total FIM scores have a potential range of (18 to 126). The higher Score demonstrating a more level of functional independent.

Tool 3: Pittsburgh Sleep Quality Index (PSQI).

The Pittsburgh Sleep Quality Index (PSQI) advanced by Kupfer DJ, (1989) $)^{13}$ is an effective tool secondhand to measure the quality and patterns of sleep in the older adult. It distinguishes "poor" from "good" sleep. It is an international measurement having seven subscales; sleep time. latency, disturbances, subjective sleep quality, the efficiency of habitual sleep, sleeping pills use, and the dysfunction of daytime over the last month. The score of sleep quality is obtained via summarizing seven elements. Each score ranged from zero to three points whereby, three reflect the negative extreme on the Liker Scale. The total PSQI ranging from 0 (no trouble) to 3 (sever trouble). The worldwide score is ranging of (0 to 21). A PSQI total score $\geq 5$ shows low sleep quality. Higher scores indicate worse sleep quality.

Method

1-An authorized approval for conducting the study was obtained from the incharge authorities.

2- Permission to conduct the study was obtained from the manager of the chest diseases hospital at kafr elsheikh governorate after explaining the purpose of the study \& identify time of data collection.

3. The permission was obtained from health care providers to COPD at 
chest hospital after the researcher introduced herself to them and explained the purpose of the study.

4-Tool I (Demographic and Clinical data structured interview schedule) was advanced by the researcher centered on review of related literatures.

5- The Arabic version of tool II (Functional Independence Measure instrument FIM) was used by the researcher in this study. The consistency was secure by spearman's correlation coefficient $(\mathrm{r}$ $=0.95)$

6 - Tool III (PSQI) was translated into Arabic language by the researcher and validity of the translation was checked by a professional of English language from the faculty of education to confirm the validity of the translation, back translation technique was used in this study.

7- Reliability of tool III was tested using test - retest methods $(r=0.94)$.

8 - The study tools [tool I (Demographic and Clinical data structured interview schedule), tool II (Functional Independence Measure instrument FIM) and Tool III (Pittsburgh Sleep Quality Index PSQI) ] were tested for content validity by a jury of 5 specialists in the fields of gerontological nursing, medical surgical nursing and public health medicine and the necessarily modification were done.

9 - Written informed agreement was gained from elderly patients before beginning of the study after explaining the purpose of the study.

10 - A pilot study was approved on 12 of elderly patients (10\%)at Kafr-El Sheikh chest diseases hospital diagnosed with chronic obstructive pulmonary disease before starting gathering information to test the probability of tools and to doing the essential modifications. These elderly patients were excluded from the study sample.

11- The researcher started the interview by introducing herself to the elderly patient giving them a brief idea about the purpose of the study and ensured that the patient was seated comfortably.

12- Each studied elderly patient was questioned individually by the researcher to gather the essential information by all study tools in the wards of the hospital.

13- The researcher started data collection based on the routine of hospital from 8 am to $1 \mathrm{pm}$ and managed to interview from 2- 3 elderly daily time consumed to fill the study tools ranged from 30 to 40 minutes.

14- A face to face interview was conducted with each elderly alone then the necessary information was gathered using the study tools. Patients' medical records were revised to complete the part of patient's medical history.

15 - The information collection within 6 months from the first January 2019 till the end of June, 2019.

\section{Ethical considerations:}

Ethical approval was gained from the Research Ethic Committee of the Faculty of Nursing, Mansoura University. Data was collected from elderly patients who are a vulnerable group therefore; extra protection is needed for this group. The study aim, benefits, risks, and procedures will be explained to elderly. The investigator ensured that the elderly understands all information about the study. To ensure confidentiality of the participants, data sheet ill included cods for the participants rather than names and 
privacy of the study subjects assured. The elderly patients assured that their sharing is voluntary, and that they have the right to accept or reject to share in this study. They have the right to extract from the study without penalty.

\section{Statistical analysis:}

Data were analyzed by statistical package of social sciences (SPSS), version 16. Data were found as number and percentages (qualitative variables) and mean $\pm \mathrm{SD}$ (quantitative continuous variables). The student's ( $\mathrm{t}$ test) and oneway a nova ( $F$ test) were used. For continuous quantitative variables which were not normally distributed, and Whitney test (Z) was used for comparison of 2 groups and Kruskal Wallis test for comparison of more than two groups. Pearson's correlation was used to find correlation between 2 quantitative variables. The difference was considered significant at $\mathrm{P} \leq 0.05$.

\section{Results:}

Table 1 revealed that, the age of the studied elderly patients fluctuated from sixty to more than eighty-five years with a mean of (70.05 \pm 8.08 years). Males were constituted $77.6 \%$ and 67.2 $\%$ were married. Illiteracy was prevailing among $47.4 \%$. Regarding residence 60.3 $\%$ of elders were living in rural areas and $82.7 \%$ reported that their income was not enough.

Table 2 demonstrates that, Hypertension was prevailing among 33.6 $\%$ of the studied elderly patients. About $54.3 \%$ of the studied elderly patients had duration of COPD since more than three years and $95.7 \%$ of the studied elderly patients had previous admission to the hospital. Moreover, $56.0 \%$ of the studied elderly patients comply with medication. Only $35.3 \%$ of them didn't comply with medication because its expense.

Table 3 illustrates the distribution of the studied elderly with COPD according to the symptoms of the disease. Dyspnea, cough and sputum were the main presenting symptoms of the studied elderly patients with COPD reported by all the studied elderly patients. Moreover $86.2 \%$ of the studied elderly patients had productive cough and $36.2 \%$ out of them had productive cough during the night.

Table 4 demonstrates that, about $50.0 \%$ of the studied elderly patients were ex-smoker and $12.1 \%$ of them were current smokers. On the other hand, $37.9 \%$ of the studied elderly never smoked. All the studied elderly patients $100 \%$ were stopped smoking due to health causes. About $80.2 \%$ of the studied elderly patients were exposed to air pollution. Also, it was found that 68.1 $\%$ of the studied elderly patients live in $>$ one subject / room and $31.9 \%$ of them live in one subject / room with mean of $1.61 \pm 0.77$.

Table 5 clarifies that, the total mean score percentage of rate of movement was Mean $\pm \mathrm{SD}=61.4 \pm$ 33.5, total mean score percentage cognitive level was Mean $\pm \mathrm{SD}=64.0 \pm$ 34.2 and total functional status Mean \pm $\mathrm{SD}=62.2 \pm 32.1$.

Figure 1 shows functional status level among the studied elderly patients with COPD. Regarding, functional status $44.8 \%$ of the studied elderly showed very good level, $36.2 \%$ of them showed poor leveland $19.0 \%$ showed good level.

Figure 2 demonstrates sleep quality of the studied elderly patients with COPD. Patients reported that 71.6 $\%$ with COPD had poor quality of sleeping while, $28.6 \%$ had good sleeping level.

Table 6 illustrates that, the functional status is significantly affected 
by age, social status and working now ( $\mathrm{P}$ $=0.001, \quad \mathrm{P}=0.008, \quad \mathrm{P}=0.001$ respectively). Also sleep quality is significantly affected by age, social status and working now $(\mathrm{P}=0.001$ in all).

Table 7 demonstrates that, there was a significant relation among functional status, quality of sleep and comorbidities. As regard the elderly patients who not suffered from any disease had higher mean score in functional status $(97.00 \pm 32.77)$ and better sleep quality (low score) $(6.44 \pm$ 3.86) than those had diseases. Also, there is a significant relation between functional status, sleep quality and time

Table (1): Demographic characteristics of the studied elderly patients with COPD

\begin{tabular}{|c|c|c|}
\hline Items & $\mathrm{N}=116$ & $\%$ \\
\hline $\begin{array}{l}\text { Age }(\text { In years): } \\
60-\text { yrs. } \\
75- \\
85+ \\
\end{array}$ & $\begin{array}{l}56 \\
39 \\
21\end{array}$ & $\begin{array}{l}48.3 \\
33.6 \\
18.1\end{array}$ \\
\hline Mean \pm SD $=$ & $70.05 \pm 8.0$ & $\operatorname{ars}$ \\
\hline $\begin{array}{l}\text { Sex: } \\
\text { Male } \\
\text { Female }\end{array}$ & $\begin{array}{l}90 \\
26\end{array}$ & $\begin{array}{l}77.6 \\
22.4\end{array}$ \\
\hline $\begin{array}{l}\text { Marital status: } \\
\text { Married } \\
\text { Unmarried (Single- Widow- Divorced) }\end{array}$ & $\begin{array}{l}78 \\
38\end{array}$ & $\begin{array}{l}67.2 \\
32.8\end{array}$ \\
\hline $\begin{array}{l}\text { Level of education: } \\
\text { Illiterate } \\
\text { Read/Write } \\
\text { Secondary } \\
\text { University }\end{array}$ & $\begin{array}{l}55 \\
27 \\
18 \\
16\end{array}$ & $\begin{array}{l}47.4 \\
23.3 \\
15.5 \\
13.8\end{array}$ \\
\hline $\begin{array}{l}\text { Occupation before retirement: } \\
\text { Working } \\
\text { Not working }\end{array}$ & $\begin{array}{l}97 \\
19\end{array}$ & $\begin{array}{l}83.6 \\
16.4\end{array}$ \\
\hline $\begin{array}{l}\text { Residence: } \\
\text { Rural } \\
\text { Urban }\end{array}$ & $\begin{array}{l}70 \\
46\end{array}$ & $\begin{array}{l}60.3 \\
39.7\end{array}$ \\
\hline $\begin{array}{l}\text { Living condition: } \\
\text { With family } \\
\text { With sons } \\
\text { Alone }\end{array}$ & $\begin{array}{l}70 \\
23 \\
23\end{array}$ & $\begin{array}{l}60.4 \\
19.8 \\
19.8\end{array}$ \\
\hline $\begin{array}{l}\text { Monthly income: } \\
\text { Not enough } \\
\text { Enough }\end{array}$ & $\begin{array}{l}76 \\
40 \\
\end{array}$ & $\begin{array}{l}65.5 \\
34.5 \\
\end{array}$ \\
\hline
\end{tabular}
patients those suffered from cough all day had higher mean score of functional status $(95.90 \pm 31.63)$ and better sleep quality (low score) $(7.00 \pm 4.09)$ than who suffered from cough at night or morning.

Figure 3 represents the association between total functional status and sleep quality of the studied elderly patients. There was a statistically strong, negative significant correlation between functional status and sleep quality. as functional status decreases, the sleep quality also decreases $(\mathrm{r}=$ $0.955, \mathrm{P}<0.001$ ). of cough. Moreover, the studied elderly 
FUNCTIONAL STATUS AND SLEEP QUALITY AMONG etc...

Table (2): Medical history of the studied elderly patients with COPD.

\begin{tabular}{|l|c|c|}
\hline Items & $\mathbf{N}=\mathbf{1 1 6}$ & $\mathbf{\%}$ \\
\hline Presence of comorbidities: & 39 & 33.6 \\
Hypertension & 33 & 28.5 \\
Diabetes mellitus & 28 & 24.1 \\
Liver disease & 16 & 13.8 \\
None & & \\
\hline Duration of COPD: & 23 & 19.8 \\
< one years & 30 & 25.9 \\
1-3years & 63 & 54.3 \\
>3 years & $\mathbf{3 . 3 6} \mathbf{1 . 7 5}$ years \\
\hline M SD & $\mathbf{3 . 5}$ years & \\
\hline Median (min- max) & 111 & 95.7 \\
\hline Previous hospital admission: & 5 & 4.3 \\
yes & \multicolumn{2}{|}{} \\
No & 65 & 56.0 \\
\hline Compliance with medications: & 51 & 44.0 \\
Yes & \multicolumn{2}{|}{} \\
No & 18 & 35.3 \\
\hline Causes of noncompliance: & 13 & 25.5 \\
Expensive & 9 & 17.6 \\
Side effects & 7 & 13.7 \\
Feeling better & 4 & 7.9 \\
Not effective & \multicolumn{2}{|c|}{} \\
Forgetfulness & \multicolumn{2}{|c|}{} \\
\hline
\end{tabular}

Table (3): Present complaints of the studied elderly patients with COPD

\begin{tabular}{|l|c|c|}
\hline Items & $\mathbf{N = 1 1 6}$ & $\mathbf{\%}$ \\
\hline Symptoms \#: & 116 & 100.0 \\
Dyspnea & 116 & 100.0 \\
Cough & 116 & 100.0 \\
Sputum & 115 & 99.1 \\
Sleep problems & 115 & 99.1 \\
Wheezing & 102 & 87.9 \\
Fatigue & 91 & 78.4 \\
Anxiety & 80 & 69.0 \\
Loss of appetite & 63 & 54.3 \\
Loss of weight & 34 & 29.3 \\
depression & 29 & 25.0 \\
Sexual dysfunction & & \\
\hline Type of cough: & 100 & 86.2 \\
Productive & 16 & 13.8 \\
Dry & $\mathbf{N}=\mathbf{1 0 0}$ & \\
Time of Productive Cough: & 42 & 36.2 \\
Nocturnal & 40 & 34.5 \\
In the Morning & 34 & 29.3 \\
All day & & \\
\hline
\end{tabular}


Reda Sobhy elsayed et. al.

Table (4): Exposures of the studied elderly patients with COPD to risk factors.

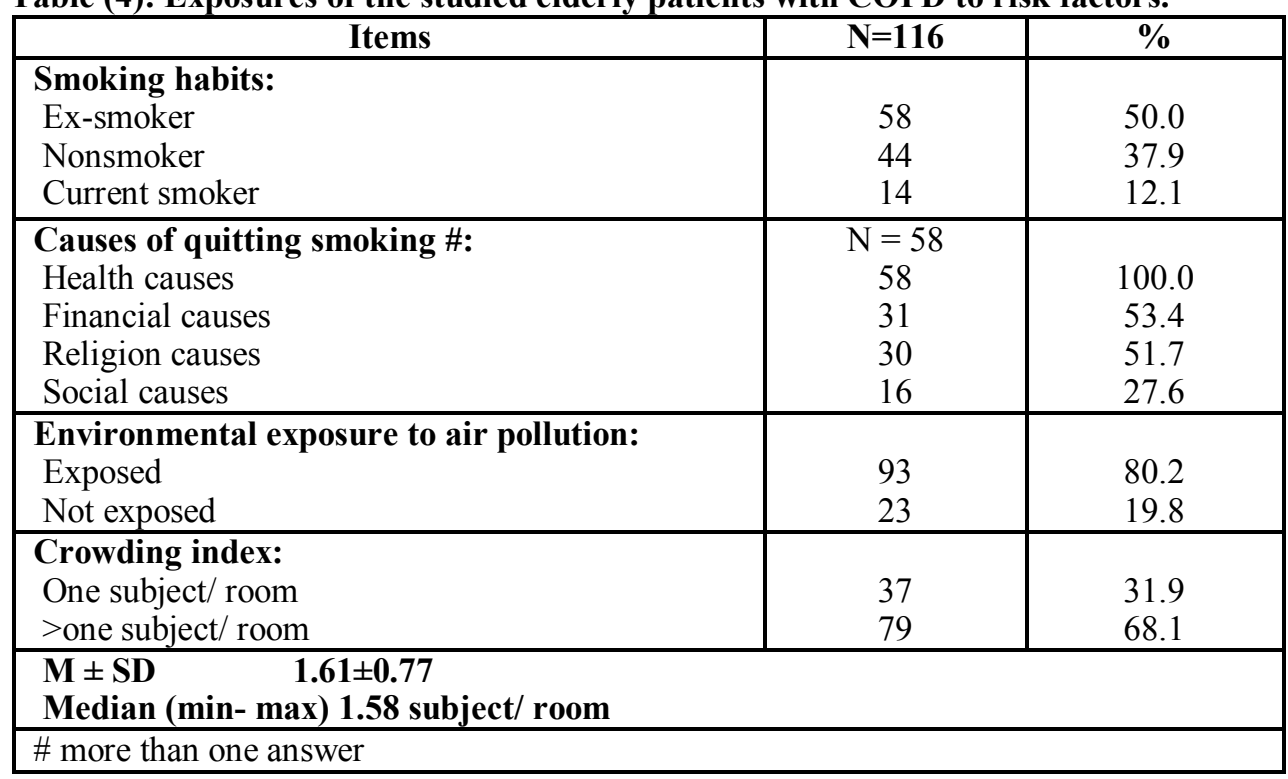

Table (5): Average total and percentage scores of functional status.

\begin{tabular}{|l|c|c|}
\hline \multicolumn{1}{|c|}{ Items } & Total Score & Total Score percentage \\
\hline A-Rate (Level) of & Range: $0-91$ & Range: $0-100$ \\
movement & Mean $\pm \mathrm{SD}=$ & Mean $\pm \mathrm{SD}=$ \\
& $55.9 \pm 30.5$ & $61.4 \pm 33.5$ \\
& Median 59.0 & Median 64.8 \\
\hline B. Cognitive level & Range: $0-35$ & Range: $0-100$ \\
& Mean $\pm \mathrm{SD}=$ & Mean $\pm \mathrm{SD}=$ \\
& $22.4 \pm 11.9$ & $64.0 \pm 34.2$ \\
& Median 20.0 & Median 57.14 \\
\hline Total functional status & Range: $0-126$ & Range: $0-100$ \\
& Mean $\pm \mathrm{SD}=$ & Mean $\pm \mathrm{SD}=$ \\
& $78.3 \pm 40.5$ & $62.2 \pm 32.1$ \\
& Median 85.0 & Median 67.5 \\
\hline
\end{tabular}

Figure (1): Functional status level among the studied elderly patients with COPD (N=116).

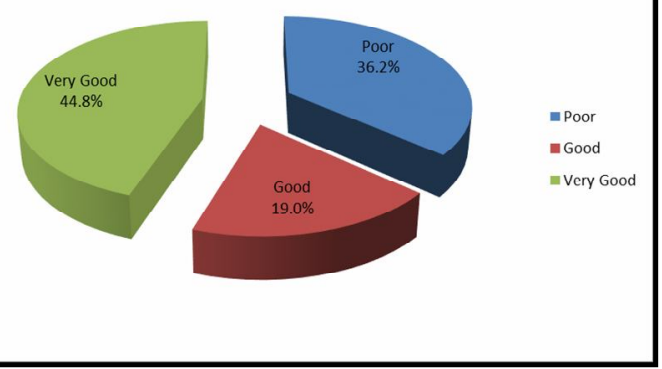


Figure (2): Sleep quality of the studied elderly patients with COPD.

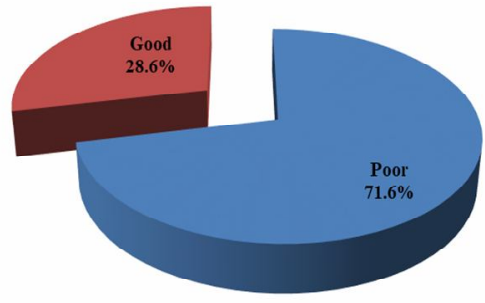

Table (6): Relation among functional status, and sleep quality and characteristics of the studied elderly patients.

\begin{tabular}{|c|c|c|c|c|}
\hline \multirow[t]{2}{*}{ Items } & \multicolumn{2}{|c|}{ Functional Status } & \multicolumn{2}{|c|}{ PSQI quality of sleep } \\
\hline & Mean \pm SD & Median & Mean \pm SD & Median \\
\hline Age: $60-$ & $74.50 \pm 26.40$ & 83.33 & $6.91 \pm 3.70$ & 5.0 \\
\hline $75-$ & $60.90 \pm 32.60$ & 67.50 & $9.10 \pm 5.06$ & 7.0 \\
\hline $85+$ & $31.70 \pm 24.40$ & 28.60 & $13.19 \pm 4.07$ & 13.0 \\
\hline Significant test & \multicolumn{2}{|c|}{$\chi^{2 *}=26.215, P<0.001$} & \multicolumn{2}{|c|}{$\chi^{2 *}=26.472, P<0.001$} \\
\hline \multicolumn{5}{|l|}{ Sex: } \\
\hline Males & $64.72 \pm 30.95$ & 73.40 & $8.39 \pm 4.48$ & 6.7 \\
\hline Females & $53.33 \pm 35.05$ & 57.14 & $10.15 \pm 5.70$ & 9.5 \\
\hline Significant test & \multicolumn{2}{|c|}{$Z^{*}=1.527$, P0.127 } & \multicolumn{2}{|c|}{$\mathrm{Z}^{*}=1.238, \mathrm{P0.216}$} \\
\hline \multicolumn{5}{|l|}{ Residence } \\
\hline Rural & $82.31 \pm 39.14$ & 97.00 & $8.53 \pm 4.81$ & 6.0 \\
\hline Urban & $72.26 \pm 42.10$ & 72.00 & $9.17 \pm 4.85$ & 9.0 \\
\hline Significant test & \multicolumn{2}{|c|}{$Z^{*}=1.104$, P0.270 } & \multicolumn{2}{|c|}{$Z^{*}=0.552, \mathbf{P 0 . 5 8 1}$} \\
\hline \multicolumn{5}{|l|}{ Social status: } \\
\hline Married & $83.52 \pm 40.36$ & 94.5 & $8.27 \pm 4.67$ & 6.0 \\
\hline Unmarried & $67.66 \pm 39.03$ & 66.5 & $9.84 \pm 4.98$ & 9.0 \\
\hline test of Significant & \multicolumn{2}{|c|}{$Z^{*}=2.176, \mathbf{P 0 . 0 3 0}$} & \multicolumn{2}{|c|}{$Z^{*}=1.690$, P0.091 } \\
\hline \multicolumn{5}{|l|}{ Education: } \\
\hline Illiterate & $65.14 \pm 31.25$ & 74.60 & $8.31 \pm 4.56$ & 6.0 \\
\hline Read/Write & $71.46 \pm 28.80$ & 83.30 & $8.00 \pm 4.63$ & 6.0 \\
\hline Secondary & $56.39 \pm 32.55$ & 57.14 & $9.50 \pm 4.93$ & 9.0 \\
\hline University & $46.18 \pm 35.61$ & 44.84 & $10.93 \pm 5.52$ & 11.0 \\
\hline test of Significant & \multicolumn{2}{|c|}{$\chi^{2 *}=5.822$, P 0.121 } & \multicolumn{2}{|c|}{$\chi^{2 *}=4.129$, P 0.248} \\
\hline \multirow{3}{*}{$\begin{array}{l}\text { Work before retirement: } \\
\text { Working } \\
\text { Not working }\end{array}$} & & & & \\
\hline & $64.11 \pm 31.02$ & 72.20 & $8.45 \pm 4.67$ & 6.0 \\
\hline & $52.26 \pm 36.47$ & 46.83 & $10.47 \pm 5.33$ & 11.0 \\
\hline test of Significant & \multicolumn{2}{|c|}{$Z^{*}=1.189$, P0.234 } & \multicolumn{2}{|c|}{$Z^{*}=1.520, P 0.129$} \\
\hline \multicolumn{5}{|l|}{ Working now: } \\
\hline Not working & $46.71 \pm 28.58$ & 45.63 & $10.87 \pm 4.59$ & 10.5 \\
\hline Working & $91.53 \pm 10.94$ & 96.03 & $4.83 \pm 1.82$ & 4.0 \\
\hline test of Significant & \multicolumn{2}{|c|}{$Z^{*}=7.758, P<0.001$} & \multicolumn{2}{|c|}{$Z^{*}=7.380, P<0.001$} \\
\hline \multirow{3}{*}{$\begin{array}{l}\text { Monthly income: } \\
\text { Not enough } \\
\text { Enough } \\
\end{array}$} & & & & \\
\hline & $80.01 \pm 40.82$ & 88.0 & $8.55 \pm 4.84$ & 6.0 \\
\hline & $75.13 \pm 40.08$ & 85.0 & $9.22 \pm 4.78$ & 8.0 \\
\hline test of Significant & \multicolumn{2}{|c|}{$Z^{*}=0.766$, P0.444 } & \multicolumn{2}{|c|}{$Z^{*}=1.174, P 0.240$} \\
\hline
\end{tabular}


Reda Sobhy elsayed et. al.

Table (7): Relation among functional status, sleep quality and medical history of the studied elderly patients.

\begin{tabular}{|c|c|c|c|c|}
\hline \multirow[t]{2}{*}{ Items } & \multicolumn{2}{|c|}{ Functional Score } & \multicolumn{2}{|c|}{ PSQI score } \\
\hline & Mean \pm SD & Median & Mean \pm SD & Median \\
\hline \multicolumn{5}{|l|}{$\begin{array}{l}\text { Duration of COPD } \\
\text { (years): }\end{array}$} \\
\hline$<$ one years & $89.87 \pm 36.42$ & 99.00 & $7.87 \pm 4.43$ & 6.0 \\
\hline 1-3 years & $83.40 \pm 39.76$ & 100.50 & $7.97 \pm 4.71$ & 6.0 \\
\hline$>3$ years & $71.70 \pm 41.46$ & 78.00 & $9.51 \pm 4.95$ & 8.0 \\
\hline Significant test & \multicolumn{2}{|c|}{$\chi^{2} *=4.270$, P 0.118} & \multicolumn{2}{|c|}{$\chi^{2 *=3.959, \text { P } 0.138}$} \\
\hline \multirow{5}{*}{$\begin{array}{l}\text { Comorbidities: } \\
\text { hypertension } \\
\text { diabetes mellitus } \\
\text { liver disease } \\
\text { none }\end{array}$} & & & & \\
\hline & $92.61 \pm 34.69$ & 105.0 & $7.15 \pm 3.77$ & 6.0 \\
\hline & $81.18 \pm 38.42$ & 85.0 & $8.63 \pm 4.99$ & 7.0 \\
\hline & $44.39 \pm 35.02$ & 36.0 & $12.57 \pm 4.34$ & 12.5 \\
\hline & $97.00 \pm 32.77$ & 105.5 & $6.44 \pm 3.86$ & 4.5 \\
\hline Significant test & \multicolumn{2}{|c|}{$\chi^{2 *}=27.826, P<0.001$} & \multicolumn{2}{|c|}{$\chi^{2 *}=26.496, P<0.001$} \\
\hline \multicolumn{5}{|l|}{ Time of Cough: } \\
\hline Morning & $81.31 \pm 40.01$ & 85.0 & $8.43 \pm 4.64$ & 6.5 \\
\hline All day & $95.90 \pm 31.63$ & 105.0 & $7.00 \pm 4.09$ & 5.5 \\
\hline Night & $53.97 \pm 39.20$ & 54.0 & $11.32 \pm 4.85$ & 11.0 \\
\hline Significant test & \multicolumn{2}{|c|}{$\chi^{2 *}=18.725, P<0.001$} & \multicolumn{2}{|c|}{$\chi^{2 *}=14.126$, P0.001 } \\
\hline $\begin{array}{l}\text { Type of cough: } \\
\text { productive }\end{array}$ & $77.21 \pm 40.52$ & 85.00 & $8.89 \pm 4.84$ & 7.5 \\
\hline Dry & $85.31 \pm 40.63$ & 92.00 & $8.13 \pm 4.77$ & 6.5 \\
\hline Significant test & \multicolumn{2}{|c|}{$Z^{*}=0.991$, P 0.321} & \multicolumn{2}{|c|}{$Z^{*}=0.678$, P 0.498} \\
\hline
\end{tabular}

Figure (3): Association between total functional status and sleep quality of the studied elderly patients

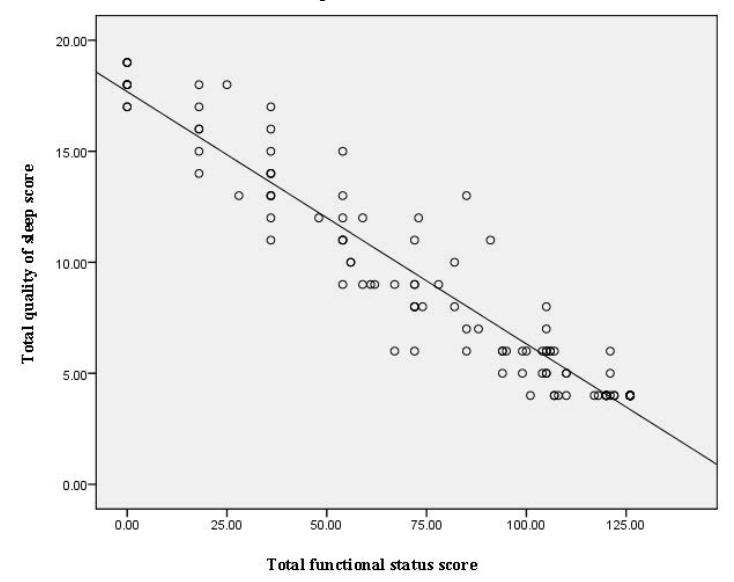

$(r=-0.955, P<0.001)$ (strong, negative significant correl ation) 


\section{Discussion}

Chronic obstructive pulmonary disease (COPD) considering a major worldwide public health problem because of increasing its mortality and morbidity. COPD disease is one of the most chronic diseases affecting elderly people all over the world because it occures in later life ${ }^{14}$.

Age is the highest powerful hazard factor for developing chronic obstructive pulmonary disease, due to age related changes in expiratory flow rates. The present study showed that, the mean age of the studied elderly patients was $70.05+8.08$ years and most of the studied elderly patients were between 60 to less than 75 years old. This result may be justified as; the prevalence of COPD is rising steadily with age due to physiological decrease in respiratory function with age. This is in accordance with a study finished by Tel et al., (2012) ${ }^{15}$ initiate that, the age of COPD patients was more than 66 years. Also, a study done by Higham et al., (2001) ${ }^{16}$ showed that the maximum number of cases in 61-70 years. And Sutradhar et al., (2019) ${ }^{17}$ reported that the frequency of COPD rise with age and old age is considered a danger factor for developing COPD. Where these studies conducted? Please mention counties of these studies.

The present study revealed that chronic obstructive pulmonary disease was encountered more among elderly men than women. This may be attributed to the facts that males are more exposed to risk factors, mainly cigarette smoking than females. This result agrees with a study carried out in Sudan by Osman et al., (2014) ${ }^{18}$ who revealed that male is predominance in the study. On the same line, a study conducted in Egypt by Badway., (2015) ${ }^{19}$ revealed that incidence of COPD among males was greater than females. In contrast with a study conducted in India by Smith., $(\mathbf{2 0 0 0})^{20}$ found that high prevalence of COPD was observed among women than men and attributed that to indoor air pollution.

In relation to marital status, the current study revealed that greatest of the studied elderly patients were marital. This result in the same line with a study prepared in Egypt by Khalil and Mostafa., (2019) ${ }^{21}$. Also, the present study revealed that illiteracy was high prevailing among the studied elderly patients. This result may be justified as; most of the studied elders were from rural areas and in the past, there was not educated in the rural areas. These results are consistent with a study done in Sweden by Anne, Lindbergh., (2004) ${ }^{22}$ who confirmed that low level of education close to significant as a risk factor for increased incidence of COPD among the symptomatic when adjusted for confounders.

Concerning occupation before retirement, the present study showed that the mainstream of the studied elderly patients was working before retirement. This result may be related to the majority of the studied elderly patients were males, working in industrial areas, working in the agriculture sector, and exposure to irritants at their workplaces. All these causing a serious lung damage. This result agrees with other studies done in Egypt by Ibrahim and Abd El Maksoud., (2018) ${ }^{23}$ and in Sweden by Anne, Lindbergh., (2004) ${ }^{22}$.

Along the same line, most of the studied elderly patients were living in rural areas. This may be are more frequently exposed to rice-grass burning, using wood, and agricultural crop residues in rural area, which lead to 
greater destruction of airway with more chest symptoms. Also, they are less able to maintain healthy lifestyle and do not have access to great quality prevention, early detection, and treatment facilities in which there is limited access to health care. All these were considered a major risk factors for developing COPD. This result is similar to Badway et al., (2015) ${ }^{19}$ study who indicated that, the prevalence of COPD is more between rural than urban Egyptian population. Also, a study conducted in Thanjavur by Ravishankar., (2007) $)^{24}$ revealed that $70 \%$ of patients were from rural areas and $30 \%$ were from urban areas.

Comorbidities is highly prevalent in chronic obstructive pulmonary disease elderly patients. The present study revealed that, hypertension was the most common comorbidities followed by diabetes mellitus and liver disease. This is the fact that progressing age is usually associated with presence numbers of chronic comorbidities and because most of the Egyptians suffer from these diseases. This result is in the same line with a study completed in Egypt by Farag et al., (2018) ${ }^{25}$ who revealed that hypertension was the most common comorbidity among COPD elderly patients tracked by diabetes mellitus. While a study done in Sudan by Osman et al., (2014) ${ }^{18}$ found that diabetes mellitus being the most frequent comorbidity followed by hypertension.

Concerning the duration of chronic obstructive pulmonary disease, most of the studied elderly patients have COPD since more than three years. This result may be due to COPD is described as a chronic slowly progressive disease of airflow obstruction. This result agrees with a study done in Egypt by El-Gendy et al., (2015) ${ }^{26}$ who found that more than half of the patients were diagnosed with
COPD for more than one year. Moreover, all most of the studied elderly patients had previous hospital admission. This is due to that, the most common symptoms of chronic obstructive pulmonary disease are dyspnea and cough which makes the elderly people need necessarily to oxygen so, they are entering the hospital.

Chronic obstructive pulmonary disease is a chronic disease in which active management needs long period compliance to pharmacotherapies. Noncompliance is important risk factor for mortality, morbidity, hospitalizations and reduce functional status ${ }^{27}$. The current study revealed that most of the studied elderly patients was adhering to medications. This is may be due to the patients sense with severe symptoms such as dyspnea and cough. Research suggests that, there are many factors influence compliance with medications and persistence with medications such as patients age, co- payment, comorbidities, concomitant medications, complexity of the treatment regimen, adverse events and dosing frequencies. (George et al., $\mathbf{2 0 0 5}^{28}$ \& cramer et al., 2007) $)^{29}$.

As regard, comply with prescribed medication the present study revealed that, minor of the studied elderly patients didn't comply with prescribed medication and the main causes of noncompliance were the expensive and side effects of medications. In contrast, Fadila., (2012) $^{30}$ study revealed that more than three quarters of the studied Egyptian elderly patients didn't comply with the prescribed medication and the main cause of noncompliance was the cost and side effect of medications. While, Hernandez et al., (2009)-showed that the improvement in symptoms was the most offered reason for stopping 
medications in Canada. Also, Bender et al., (2006) $)^{32}$ reported that, withdrawal of medicine in USAmay occur due to range of reasons, such as reduced symptomatology or the complexity of treatment schedules.

Chronic obstructive pulmonary disease is a main reason of disability and impairment of quality of life in the elderly patients and the degree of this impairment mainly depends on the severity and frequency of symptoms experienced by patients ${ }^{1}$. The present study revealed that dyspnea, cough and sputum were the most frequently reported complaints by all the studied elderly patients. The presence of dyspnea is due to COPD is defined as chronic slowly progressive disease of airflow obstruction and the presence of cough due to the presence of chronic bronchitis characterized by mucus hyper-secreation in responce to chronic irritation of the air ways followed by wheezing while sexual dysfunction reported the lowest percentage. This result is congruent with a study done in Egypt by Fadila., $\mathbf{( 2 0 1 2 )}^{\mathbf{3 0}}$ who revealed that dyspnea was the most frequently reported complaints followed by cough, wheezing, sleep disturbance and fatigue while sexual dysfunction represented the lowest percentage. Also, a study done in Egypt by Ibrahim and Abd El - Maksoud., (2018) $^{23}$ found that, most of the studied patients had cough, sputum, dyspnea, and restlessness. While contradicts with a study conducted in Spain by Ibazen et al., (2001) $)^{33}$ who speculated that sexual problems such as lack of desire and impotence were reported by $67.3 \%$ of COPD. This discrepancy, in relation to sexual problems, may be attributed to culture where Egyptian males were difficult to admit sexual problems, as it was considered a stigma against their masculinity.

Tobacco is considered a major risk factor and important initial diagnostic for chronic obstructive pulmonary disease. (Van Eerd et al., 2016) ${ }^{34}$. The current study revealed that most of the studied elderly patients were either ex- smoker. This finding was supported by a study done in Sudan by Osman et al., (2014) ${ }^{18}$ who found that more prevalent of study sample in eversmokers compared to non - smoker. Another study conducted in Spain by Leiva - Fernández et al. (2014) ${ }^{35}$ found high incidence in the male sex, most likely because of the smoking habits. On the same line, a study carried out in Rewanda by Musafiri et al., (2011) ${ }^{36}$ determined the incidence and risk factors of asthma, and COPD was related to cigarette smoking, age and male sex.

As regard environmental exposure, majority of the studied elderly patients were exposed to environmental exposure as air pollution (fossil fuel, motor vehicle). This result may be justified as; most of the studied elders recognized biomass fuel use as a danger factor for increasing chronic obstructive pulmonary disease specifically among rural females. This finding is in this respect with a study done by Ispita Sutradhar et al., (2019) ${ }^{37}$ who reported that, exposure to biomass smoking increases the hazard of developing COPD, particularly in females. Also, a modern retrospective cohort study conducted in Bangladesh by Alam et al., $\mathbf{( 2 0 1 2}^{38}$ found that, morbidity and mortality from lung diseases as COPD and chronic bronchitis are greater between biomass fuel workers.

The present study revealed that functional status was very good in most of the studied elderly patients and 
adequate number were good. This result may be related to the efficiency of management, effective care provided and the planned follow-up and living with the family. This result in the same line with a study finished in U.S by Khan et al., (2013) $^{39}$ who revealed that physical activity was stable. Moreover, this result disagreed with a study done by Rgarrod et al., (2000) $)^{40}$ who revealed that activities of daily living (ADL) may be strictly limited in patients with COPD. On the other hand, minor of the studied elderly patients had poor functional status this was due to the increased age and severity of COPD. This result in the same line with a study prepared by Watz, et al., (2009) ${ }^{41}$ who found that physical activity is reduced in patients with COPD. Also, a study done by Florence et al., (2000) ${ }^{42}$ revealed that anxiety and depression contributed to the overall variation in functional status of COPD patients.

Moreover, the result of the present study revealed that, most of the studied elderly patients had poor quality of sleep. This is may be due to symptoms such as dyspnea, productive cough, and administration of nebulizer sessions, as major concerns in patients with COPD. This result is consistent with a study done in Egypt by Khalil, Mostafa and Ahmed., (2019) ${ }^{21}$ who revealed that mainstream of patients had the insufficient of sleep quality. Also, a study done in Thailand by Kulpatcharapong., et al., (2019) ${ }^{43}$ demonstrated high incidence of poor sleep quality. Moreover, the study findings agree with a study done by Sharma, et al., (2016) ${ }^{44}$ examined quality of life and quality of sleep between COPD patients and found that more than two-thirds of the patients had poor quality of sleep.
Moreover, this study reveals that, minor of the studied elderly patients had good sleep quality. In support with these findings a study done by Weeracorn et al., (2018) ${ }^{45}$ who reported lower prevalence had good sleep quality. Along the same line a study done by Ohayon et al,(2017) ${ }^{46}$ who revealed that sleep quality is considered good.

Functional status of elderly patients with chronic obstructive pulmonary disease affected by several features in term of demographic characteristics including age, sex, social status, education, residence, working before retirement, working now, the income and living condition ${ }^{53}$. The present study discovered that, there was a significant relation between functional status and age. This can be explained by the severity of the disease is increased by aging due to physiological changes especially respiratory system and noncompliance with treatment regimen ${ }^{54}$. revealed that elderly patients with COPD have a more severe deterioration of the functional status. Moreover, social status affects significantly on functional status. This result in agreement with a study carried out in Egypt by Badr and Shaheen., (2016) ${ }^{47}$ who found a significant difference regarding marital status. Also, there was a significant relation between functional status and working now. This is agreeing with change., (2015) $)^{48}$.

This study displayed that there was no significant relation between sex and functional status. Female had greater problem (less in functional status than male). This is agreed with a study ended by Jersey, Joan and Bennett et al., (2008) $^{49}$ found that the deteriorating of functional status was more accelerated among women and older age groups. Also, there was no significant relation 
between residence and functional status. The results of his study revealed that the elderly people who lived in rural area had higher score in functional status rather than who lived in urban areas. This is explained by the fact that the living in rural area is best due to the people don't expose to air pollutions from cars, factories and there was no overcrowded as urban area This is in the same line with a study done by crisan et al., $(2014)^{50}$.

Moreover, the present study discovered that a significant relation was initiate between comorbidities and functional status. As the presence of comorbidities may lead to increase severity of disease process and decrease in functional status. This results in the same line with a study done in India by Shay.,(2017) ${ }^{51}$ who revealed that diseases affects functional status and physical activity in patients with COPD. Moreover, this study revealed that, there was a significant relation was created between time of cough and functional status. The elderly patients who had cough all day had a higher score in functional status this may be justified by cough was intermittent not persistence. Along with the same line with ${ }^{8}$.

Sleep is considered one of the basic activities of human daily living, and it affects physically and mentally in human health ${ }^{52}$. Concerning the relation between characteristics of the studied elderly patients and sleep quality, there was a significant relation found between age and quality of sleep. This is congruent with a study finished in Egypt by Khalil et al., (2019) ${ }^{21}$. In contrast, Geiger et al., (2015) ${ }^{53}$ initiate that there was a statistically significant negative relationship between quality of sleep and age. Also, there was a significant relation between sleep quality and social status.
The result of the present study revealed that married patients had good quality of sleep than unmarried. This result may be justified as; married patients had life satisfaction due to presenting with love family. Along the same line with a study prepared by Zohale, et al., (2014) ${ }^{54}$. Also, there was a significant relation between quality of sleep and working now. As patients who reported working had good sleep quality than who are not working. This result may be justified as; working is considered activity that enhance sleep and relieve psychological features that lead to good sleep quality. This result is similar to a study finished by Dignani, et al.,(2016) ${ }^{55}$.

Also, there was no significant relation between sex and quality of sleep. As female had poor sleep quality compared with male. This result disagreed with a study prepared in Egypt by Zamzam et al., (2020) ${ }^{56}$ who found that there was a significant relationship between Pittsburgh Sleep Quality Index score and sex. Also, there was no significant relation between residence and quality of sleep. As this study revealed that the elderly people who are living in rural area had good sleep quality rather than who are living in urban area because rural area are quite and street free from cares noisy and overcrowded of populations. This result was in disagreement with a study done by lee chiong ${ }^{57}$ \&park, $(\mathbf{2 0 1 7})^{58}$ whom discovered that there was a significant poor quality of sleep in rural elderly patients.

Moreover, there was a significant relation between comorbidities and sleep quality. Along the same line with a study completed by Chia-Yi Wu et al., (2012) ${ }^{59}$ who revealed that the effect of chronic disease, hypertension, cardiovascular disease, endocrine, 
musculoskeletal disease, and metabolic disease were linked to quality of sleep. Also, there was a significant relation between time of cough and sleep quality. The current result contradicted with Fiona et al., (2016) ${ }^{60}$ found that there was a significant associations found between nocturnal symptoms and sleep disturbances. Also, a study done by Scharf et al., (2011) ${ }^{61}$ initiate a significant association between the number of nocturnal symptoms and sleep time.

The present study revealed that, there wasn't any significant relation among duration of COPD, type of cough and sleep quality. This results in contrast, with a study completed by Hartman et al., (2015) ${ }^{62}$ who inspected the association between frequent sputum production and impaired sleep quality in chronic obstructive pulmonary disease patients.

There was a statistically negative statistically correlation between functional status and sleep quality. As functional status decrease, the sleep quality also decrease. in support of this findings a study prepared by Rui Chen, et al., (2016) ${ }^{63}$ who found that, there was a close association between functional capacity and quality of sleep in patients with COPD.

\section{Conclusion}

Based on the results of the current study it can be concluded that, chronic obstructive pulmonary disease is a common disease among elderly especially male patients. Smoking is the major danger factor for increasing chronic obstructive pulmonary disease. Moreover, functional status and sleep quality in the elderly patients with chronic obstructive pulmonary disease are depending on several factors including age, social status and duration of disease. In additionally functional status is adequately reported very good and most of the studied elderly patients suffering from poor sleep quality. Also, negative correlation was initiate between functional status and sleep quality indicating that when functional status increase, the sleep quality also increase.

\section{Recommendations}

Development of comprehensive simple Arabic printed educational materials such as pamphlets, books. Electronic educational materials such as videos to:

1-Increase awareness of the elderly patients about risk factors of chronic obstructive pulmonary disease.

2-Improve functional status and sleep quality of elderly patients by giving instructions to adapt healthy lifestyle and avoid risk factors of chronic obstructive pulmonary disease,

\section{References:}

[1] Centers for Disease Control and Prevention. (2009). Available at: http://www.cdc.gov. Accessed on 28 /3/2018.

[2] Johnson, P., Balakrishnan, K., Ramawswamy, P., Ghosh, S., Sadhasivam, M., Abirami, O., Sathiasekaran, B., kirk, R. (2011). Prevalence of chronic obstructive pulmonary disease in rural women of Tamilnadu: implications for refining disease burden assessments attributable to household biomass combustion. Journal Glob Health Action, 4 (4), 7226. Accessed on $15 / 8 / 2019$.

[3] Klingman, KJ., Jungquist, CR., Perlis, ML. (2017).Questionnaires that screen for multiple sleep disorders. Sleep Med Rev, 32, 3744. 
[4] Van Remoortel, H., Hornikx, M., Demeyer, H., Langer, D., Burtin, C\& Decramer, M. (2013). Daily physical activity in subjects with newly diagnosed COPD. Thorax, 68 (10), $962-3$.

[5] Gimeno-Santos, E., Raste, Y., Demeyer, H., et al. (2015). The Proactive instruments to measure physical activity in patients with chronic obstructive pulmonary disease. Eur Respir Journal, 46(4), 988-1000.

[6] Lenferink, A., Frith., P van, P., Buckman, J., Sladek, R.,\& Cafarella, p. (2013). A selfmanagement approach using selfinitiated action plans for symptoms with ongoing nurse support in patients with chronic obstructive pulmonary disease (COPD) and comorbidities: the COPE- III study protocol. Contemp Clin Trials, 36 (1), 81-9.

[7] Wang, Y., Hu, k., Liu, K., Li, Z., Yang, j., Dong, Y. (2015). obstructive sleep apnea exacerbates airway inflammation in patients with chronic obstructive pulmonary disease. journal of Medicine, 16 (9), 1123 - 30.

[8] Global initiative for Chronic Obstructive lung Disease. (GOLD) (2014). Global strategy for the diagnosis, management, and prevention of chronic obstructive pulmonary disease. Available at: http://www gold copd.org. Accessed on $10 / 2$ / 2018.

[9] Calik-Kutukcu, E., Arikan, H., Saglam, M., et al. (2015). A comparison of activities of daily living in geriatric and non-geriatric patients with chronic obstructive pulmonary disease Turk Journal Geriatric, 18, 68-74.
[10] Hamilton, B., Granger, V., Sherwin S., (1987). A uniform national data system for medical rehabilitation. In: Fuhrer $\mathrm{M}$, ed. Rehabilitation outcomes: Analysis and measurement. Baltimore: Brookes, 1987:137-147. Available at: http://www.tbims.org.

Accessed on 11/ 1/ 2018.

[11] Center for Medicare and Medicaid Services. (2003). The inpatient Rehabilitation Facility -Patient Assessment Instrument (IRF- PAI) Training Manual. UB Foundation Activities. Available at: http://www.cms.gov. Accessed on 10/ 1/ 2018.

[12] Shebl, A.M., \& Abd Elhameed, S.H. (2014). Impact of Informal Caregivers Training Program on Geriatric patients functional status and depression. IOSR Journal of Nursing and Health Science, 4 (3), $45-53$.

[13] Buysse D. J., Reynolds, C.F, Monk, T.H, Berman, S.R, and Kupfer, D.J. (1989). The Pittsburgh Sleep Quality Index (PSQI): A new instrument for psychiatric research and practice. Journal Psychiatry Research, 28 (2), 193 - 213.

[14] Bakke, P.S. (2013). Comorbidities in current COPD guidelines. Eur Respir Mon, 59: 217-222.

[15] Tel., et al.(2012). Thesis in chronic obstructive pulmonary disease to estimate the prevalence, incidence of COPD, risk factors for COPD and decline in lung function.

[16] Higam.(2001). Introduction to numerical simulation of stochastic differential questions. SIAM Review, 43 (3), $525-546$. 
[17] Sutradhar, I., Gupta, RD., Hasan, M., Wazib, A., Sarker, M., (2019). Prevalence and risk factors of chronic obstructive pulmonary disease in Bangladesh: A Systematic Review.Cureus,11(1), e3970. https://doi.org/10.7759/cureus.3970.

[18] Osman, Rashid., (2014). Thesis about prevalence and risk factors of chronic obstructive pulmonary disease.

[19]Badway, S.H., Hamed, A.F., Yousef, F.(2015). Prevalence of chronic obstructive pulmonary disease. Egyptian journal of chest disease and tuberculosis, 65 (1).

[20] Smith, KR., (2000). Inaugural Article: national burden of disease in Indian from indoor air pollution. Proceedings of National Academy of science of United State of America; 97:286 - 293.

[21] Khalil, S., Mostafa, F., Ahmed, Y. (2019). Sleep quality among patients with chronic obstructive pulmonary disease at a university hospital in Egypt in Clinical Practice, 16(2).

[22] Anne, Lindberge., et al. (2004). Prevalence, incidence, decline in lung function and risk factors of chronic obstructive pulmonary disease.

[23] Ibrahim, A.S\& El Maksoud, M.M.(2018). Effect of educational program knowledge and selfmanagement of patients with chronic obstructive pulmonary disease. Original article, 15 (3), 245 - 257.

[24] Ravishanker.(2007). study on chronic obstructive pulmonary diseases.
[25] Farag, S., et al. (2018). Evaluationof health-related quality of life in patients with chronic obstructive pulmonary disease.originalarticle, 12 (3), 288 294.

[26] Elgendy, R.S., et al. (2015). Controlling dyspnea in chronic obstructive pulmonary disease patients. journal of Egyptian public health Association, 90 (2), 58 - 63.

[27] Global Initiative for Chronic Obstructive Pulmonary Disease (GOLD).(2016). The global strategy for the diagnosis ,management and prevention of COPD. Available from:http://goldcopd.org/ (Accessed on 30/8/(2019).

[28] George, J., Kong, D., Thoman, R., et al. (2005). Factors associated with medication non adherence in patients with COPD. Chest, 128 (5), 3198 - 3204.

[29]Cramer, JA., Bradley - Kennedy, C., \& Scalera, A. (2007). Treatment persistence and compliance with medication for chronic obstructive pulmonary disease. Can Respire Journal, 14 (1): $25-29$.

[30] Fadila, D. (2012). Effect of pulmonary rehabilitation program on the quality of life of elderly patients with chronic obstructive pulmonary disease.

[31] Hernadez, P., Balter, M., Bourbeau, J., et al. (2009). Living with chronic obstructive pulmonary disease: a survey of patients knowledge and attitude. Respire med, 103:1004 - 1012 . 
[32] Bender, BG., Pedan, A., and Varasten, LT. (2006). Adherence and Persistence with fluticasone propionate / salmeterol combination therapy. Journal Allergy Clin Immunol, 118 (4), 899 - 904.

[33] Ibazen, M., Aguilar, Farrero, E., et al. (2001). Sexuality in chronic respiratory failure: coincidences and divergences between patient and primary cargiver. Respirmed, 95 (12), 975 - 979.

[34] Van Eerd, EA., van der Meer, RM., van Schayck, OC., Kotz D. (

2016). Smoking cessation for people with chronic obstructive pulmonary disease. Cochrane Database Syst Rev, (8), CD010744.

[35]Leiva, Fernadez., et al. (2014). Study for randomized, controlled trail comparing the efficacy oftwo educational interventions to improve inhalation techniques in patients with chronic obstructive pulmonary disease.

[36] Musafiris., Van Meerbeek, J., Musango L., et al. (2011). Prevalence of atopy, Asthma and COPD in an urban and rural area of an African country. Respirmed, 105(11), 1596 - 1605.

[37] Ispita, Sutradhar., et al. (2019). Prevalence and risk factors of chronic obstructive pulmonary disease in Bangladesh. A Systematic Review Cureus 11(1), 3970.

[38]Alam, DS., Chowdhury, MA., Siddiquee, AT., et al. (2012).Adult cardiopulmonary mortality and indoor air pollution: a 10-year retrospective cohort study in a lowincome rural setting. Glob Heart, 7:215-22.
[39] Khan, MN., Islam, MM., Islam, MR., Rahman, MM. (2013). Household air pollution from cooking and risk of adverse health and birth outcomes in

Bangladesh: a nationwide population-based study. Environ Health, 16 - 57.

[40]Rgarrod. (2000). Thesis in chronic bronchitis and chronic obstructive pulmonary disease.

[41]Watz, H., B, Waschki, T., Meyer, H., Magnussen. (2009). Physical activity in patients with COPD. European Respiratory Journal, 33: 262-272.

DOI: 10.1183/09031936.00024608.

[42]Florence, H., SeungKim, M.D., Mark, E., Kunik, M.D., Victor, A., Molinari. (2000). Functional impairment in COPD patients: The Impactof Anxiety and Depression Psychosomatics, 41(6), $465-471$.

[43]Santi, Kulpatcharapong., et al. (2019). Research article sleep quality of hospitalized patients, contributing factors, and prevalence of associated disorders Hindawi sleep disorders. Article ID 8518396, 7 https://doi.org/10.1155/2020/851 $\underline{8396}$.

[44]Sharma, K., Choyal, T., Chaturvedi, H., Pandey, R.(2016). Sleep quality and quality of life in patients with COPD. Chest, 150(4), 895.

[45]Weeracorn et al. (2018).study on sleep quality in elderly patients with chronic obstructive pulmonary disease.

[46]Ohayon, M., Wickwire, E. M., Hirshkowitz, M., Albert, S. M., et al. (2017). National Sleep Foundation's sleep quality. 
[47]Badr, S., Shaheen, H. (2016). Thesis in health status, family support and depression among residents of elderly homes and those living with families in benha city and associated factors.

[48]Chang, C.H. (2015). Risk factors and prevention of chronic obstructive pulmonary disease, China Prac. Med, 10 (1), 96 - 97. http://dx.doi.org/10.14163/j. cnki.

[49]Jersey., Liang., Joan, M., Bennett., Benjamin, A., Shaw., Ana, R., Quiñones., et al. (2008). Gender differences in functional status in middle and older age: are there any age variations? Journal Gerontological B Psychological Sci Soc Sci, 63(5), 282-292.

[50]Crişan, AF., Oancea, C., Timar, B., Fira-Mladinescu, O., Crişan, A., Tudorache, V. (2014). Cognitive impairment in Chronic Obstructive Pulmonary Disease. PLoS One, 9(7), 102468.

[51]Shay, A., \& Fulton, J. (2017). Hospital associated functional status decline in older adults with chronic obstructive pulmonary disease. Sigma Theta Tau International 28th International Nursing Research Congress. Dublin, Ireland. Podium.

[52]Kamphuis, J., Meerlo, P., Koolhaas, J. M., and Lancel, $M$. (2012). "Poor sleep as a potential causal factor in aggression and violence,"

[53]Geiger, Brown, J., Lindberg, S., Krachman, S., et al. (2015). Selfreported sleep quality and acute exacerbations of chronic obstructive pulmonary disease. Internal Journal Chronic Obstructive Pulmonary Disease, 10, 389 - 397.
[54]Zohal, MA., Yazdi, Z., Kazemifar, AM., Mahjoob, P., Ziaeeha, M. (2014). Sleep quality and quality of life in COPD patients with and without suspected obstructive sleep apnea. Sleep Disord, 4(2),150.

[55]Dignani, L., Toccaceli, A., Lucertini, C., Petrucci, C., Lancia, L., (2016). Sleep and quality of life in people with COPD: a descriptivecorrelational study. Clin. Nurs. Res, 25(4), 432-447.

[56]Zamzam, packnahad., et al. (2020). association of dietary quality indices with sleep quality in chronic obstructive pulmonary disease patients.

[57]Lee Chiong, T. (2017). Chronic Obstructive Pulmonary Disease and sleep. Current Respiratory Care Reports, 2(2), 123-129.

[58]Park, MJ., Kim, KH. (2017). What affects the subjective sleep quality of hospitalized elderly patients? Geriatric.

Gerontological.International, 17(3), 471- 479.

[59]Chia-Yi, Wu., Tung-Ping, Su., et al. (2012). Sleep quality among community-dwelling elderly people and its demographic, mental, and physical correlates. journal of Chinese medical association, 75 (2), $75-80$.

[60]Fiona, Cleutjens., Martijin A, Spuit., Rudolf, ponds. (2016). Cognitive impairment and clinical characteristics in patients with chronic obstructive pulmonary disease. chronic respiratory disease, 15(1). 
[61] Scharf, SM., Maimon, N., SimonTuval, T., Bernhard-Scharf, BJ., Reuveni, H., Tarasiuk, A. (2011). Sleep quality predicts quality of life in chronic obstructive pulmonary disease. Internal Journal Chronic Obstructive Pulmonary Disease, 6 12.
[62]Hartman, JE., Prinzen, J., Van Lummel, RC., Ten Hacken, NH. (2015). Frequent sputum production is associated with disturbed night's rest and impaired sleep quality in patients with COPD. Sleep Breath, 19(4), 1125-1133.

[63] Rui chen., Jing- wei, Tian., Luqian., Zhou.(2016). The relation between sleep quality and functional exercise capacity in COPD. The clinical respiratory journal, 10(4). 